\title{
Avaliação de diferentes osmolaridades de soluções hiposmóticas e tempos de incubação no teste hiposmótico do sêmen de touros Nelore
}

\author{
Leonardo Franco Martins ${ }^{1}$, Rogério Oliveira Pinho ${ }^{1}$, Renan Moreira Paraizo ${ }^{1}$, Renan Reis de \\ Oliveira $^{2}$, Erick Fonseca Castilho ${ }^{1}$, José Domingos Guimarães ${ }^{1}$
}

1 Departamento de Medicina Veterinária da Universidade Federal de Viçosa.

2 Departamento de Zootecnia da Universidade Federal de Viçosa.

RESUMO - O objetivo neste estudo foi avaliar diferentes osmolaridades e tempos de incubação durante o teste hiposmótico e suas correlações com a congelabilidade do sêmen de touros zebuínos. Foram utilizados 30 ejaculados de seis touros adultos da raça Nelore. No sêmen in natura foi feita avaliação física e morfológica, classificação quanto à coloração supravital e o teste hiposmótico. No teste hiposmótico foram utilizadas soluções com osmolaridades de 60, 100, $150 \mathrm{mOsm} / \mathrm{kg}$ e água destililada (19 mOsm $/ \mathrm{kg}$ ) om 15, 30 e 60 minutos de período de incubação a $37^{\circ} \mathrm{C}$. Após a criopreservação, as amostras foram descongeladas e avaliadas quanto aos testes hiposmótico, à coloração supravital, ao teste de termorresistência lento e à coloração fluorescente. Não foram detectadas interações entre os tempos e as osmolaridades. Não houve diferenças para os valores médios de espermatozoides reativos incubados nas soluções com diferentes osmolaridades para o sêmen congelado/ descongelado. Apenas a utilização de água destilada determinou diferença nos valores médios obtidos no teste hiposmótico realizado no sêmen in natura. Não houve diferença entre os valores médios de espermatozoides reativos incubados com diferentes tempos de incubação, tanto no sêmen in natura como no sêmen congelado/descongelado. O teste hiposmótico pode ser realizado com 15 minutos de incubação, e com uma solução que varie a osmolaridade de 60 a $150 \mathrm{mOsm} / \mathrm{kg}$, tanto no sêmen in natura como no sêmen congelado/descongelado.

Palavras-chave: Bos indicus, criopreservação, espermatozoide, testes complementares

\section{Evaluation of different osmolarity among hiposmotic solutions and incubation time in hiposmotic test of Nellore bulls semen}

\begin{abstract}
The objective of this study was to evaluate different osmolarities and incubation times during the hiposmotic test and its correlation with cryopreservation of semen of Zebu bulls. It was used 30 ejaculates from six mature Nelore bulls. It was performed physical and morphological evaluation, supravital staining classification and hiposmotic test in the fresh semen. In the hiposmotic test, solutions with osmolarities of $60,100,150 \mathrm{mOsm} / \mathrm{kg}$ and distilled water $\left(19 \mathrm{mOsm} / \mathrm{kg}\right.$ ) were used at 15,30 and 60 minutes of incubation at $37^{\circ} \mathrm{C}$. After cryopreservation, the samples were thawed and evaluated for hiposmotic test, supravital staining, slow termoresistance test and for fluorescent stain. No interactions were detected between incubation times and solution osmolarities. There were no differences in average values of reactive sperm incubated in different solutions with different osmolarities for frozen/thawed semen. Only the use of distilled water determined differences in the average values obtained in the hiposmotic test performed in fresh semen. There was no difference between the mean values of reactive spermatozoa incubated with different incubation time in both fresh and frozen/thawed semen. Hiposmotic test can be accomplished in 15 minutes of incubation time and with a solution which varies osmolarity from 60 to $150 \mathrm{mOsm} / \mathrm{kg}$ in both fresh and frozen/thawed semen.
\end{abstract}

Key Words: Bos indicus, complementary tests, cryopreservation, spermatozoa

\section{Introdução}

O teste hiposmótico avalia a atividade bioquímica da membrana plasmática intacta, devido ao influxo de água para o interior das células. Vários autores têm observado em sêmen in natura e congelado/descongelado que a integridade funcional da membrana plasmática avaliada pelo teste hiposmótico é uma importante ferramenta complementar para predizer a capacidade de fertilização do sêmen de bovinos (Bacinoglu et al., 2008). No entanto, não se entende completamente os resultados obtidos no teste hiposmótico, como também não existe padronização do protocolo para a realização da técnica em relação ao tempo de incubação e à osmolaridade da solução para sêmen de bovinos. 
Vários tempos de incubação em soluções hipósmóticas são relatados em estudos anteriores: 5 minutos (Correa et al., 1997), 20 minutos (Tartaglione \& Ritta, 2004), 30 minutos (Mocé \& Graham, 2008) e principalmente 60 minutos (Bacinoglu et al., 2008; Vera-Munoz et al., 2009). Em relação à solução hiposmótica, a osmolaridade de 150 mOsm/kg é a mais utilizada para a realização do teste no sêmen in natura (Revell \& Mrode, 1994), e $100 \mathrm{mOsm} / \mathrm{kg}$ para o sêmen congelado/descongelado (Revell \& Mrode, 1994; Correa \& Zavos, 1994). O teste hiposmótico avalia um importante aspecto de qualidade dos espermatozoides, mas não é utilizado como rotina nas avaliações andrológicas porque não existem parâmetros estabelecidos para a classificação de reprodutores. Vários estudos devem ser realizados para melhor compreensão dos seus resultados, mas a falta de padronização da técnica é prejudicial, principalmente para a comparação dos resultados de diversas pesquisas.

Neste estudo, o objetivo foi avaliar diferentes osmolaridades e tempos de incubação na realização do teste hiposmótico e suas relações com a qualidade e congelabilidade do sêmen in natura e congelado/ descongelado (medidos pelos testes de termorresistência, supravital e coloração fluorescente) de touros adultos da raça Nelore.

\section{Material e Métodos}

Foram utilizados neste experimento seis touros adultos da raça Nelore, com 4 a 7 anos de idade, criados em condições extensivas no Setor de Gado de Corte da Universidade Universidade Federal de Viçosa. Foram obtidos pelo método de eletroejaculação cinco ejaculados por touro e realizadas duas coletas por semana. No sêmen in natura, foram feitas as avaliações física e morfológica (CBRA, 1998), determinada a coloração supravital e o teste hiposmótico. Posteriormente, cada ejaculado foi congelado em palhetas de polietileno $(0,25 \mathrm{~mL})$ com 30 milhões de espermatozoides totais por dose, conforme protocolo preconizado por Senger (1986). Foram utilizadas 5 horas de período de equilíbrio em geladeira a $4^{\circ} \mathrm{C}$, e 15 minutos a $-80^{\circ} \mathrm{C}$ (vapor do nitrogênio líquido) para posterior submersão e estocagem em nitrogênio líquido $\left(-196^{\circ} \mathrm{C}\right)$. Foram congeladas 20 palhetas por ejaculado e três delas foram descongeladas para realização dos testes complementares (hiposmótico, coloração supravital, coloração fluorescente e teste de termorresistência lento).

Para o teste hiposmótico, foram utilizadas soluções de citrato de sódio e frutose com osmolaridades de 60, 100, $150 \mathrm{mOsm} / \mathrm{kg}$ (Tabela 1) e água destilada (19 mOsm/kg) com 15,30 e 60 minutos de período de incubação a $37^{\circ} \mathrm{C}$. As osmolaridades foram ajustadas e aferidas pelo método crioscópico (Henriques \& Rosado, 1999), acrescentando mais água destilada. Depois do período de incubação, foram acrescentados $0,5 \mathrm{~mL}$ de solução de formol salina para a fixação dos espermatozoides e posteriormente feita a análise em microscopia de contraste de fase. Foram contabilizados 100 espermatozoides em aumento de $1000 \mathrm{X}$ e obtido o percentual de espermatozoides com flagelo curvando-se junto à membrana expandida, para depois ser calculada a porcentagem de espermatozoides reativos, subtraindo do percentual de flagelos dobrados registrado no sêmen in natura (Melo \& Henry, 1999). O mesmo procedimento foi utilizado para a realização do teste hiposmótico do sêmen congelado/descongelado.

A coloração supravital foi utilizada para avaliação da integridade física da membrana plasmática, utilizando solução de eosina (1\%) e nigrosina (5\%), conforme descrito por Swanson \& Bearden (1951). Após a confecção de um esfregaço em lâmina pré-aquecida a $37^{\circ} \mathrm{C}$, foram contabilizadas 100 células espermáticas (aumento de 400x): as células íntegras permaneceram sem corar e aquelas com danos à membrana coraram-se de rosa avermelhado. O mesmo procedimento foi realizado para a avaliação do sêmen congelado/descongelado.

Para avaliação da motilidade progressiva retilínea e do vigor dos espermatozoides sob estresse térmico, foi aplicado o teste de termorresistência lento em amostras de sêmen congelado/descongelado, conforme descrito por Siqueira et al. (2007). O sêmen congelado em palhetas de 0,25 mL, após seu descongelamento a $37^{\circ} \mathrm{C}$ por 30 segundos, foi acondicionado e homogeneizado em tubos plásticos de 1,5 mL. Durante o período de incubação, as amostras de sêmen foram avaliadas quanto aos aspectos de motilidade espermática progressiva retilínea e o vigor espermático nos intervalos de $0,60,120,180$ minutos.

A avaliação da membrana plasmática da cabeça e dos acrosomos dos espermatozoides das amostras de sêmen in natura e congelado/descongelado foi realizada com associação de duas sondas fluorescentes (diacetato de carboxifluresceína e iodeto de propídeo), conforme proposto por Harrison \& Vickers (1990). Em microscopia de

Tabela 1 - Composição química das soluções hiposmóticas utilizadas no teste hiposmótico realizado em sêmen bovino in natura e congelado/descongelado de touros Nelore

\begin{tabular}{lccc}
\hline & \multicolumn{4}{c}{ Osmolaridade } \\
\cline { 2 - 5 } Componente & $60 \mathrm{mOsm} / \mathrm{kg}$ & $100 \mathrm{mOsm} / \mathrm{kg}$ & $150 \mathrm{mOsm} / \mathrm{kg}$ \\
\hline D-frutose & $5,4 \mathrm{~g}$ & $9 \mathrm{~g}$ & $13,5 \mathrm{~g}$ \\
Citrato de sódio & $2,9 \mathrm{~g}$ & $4,9 \mathrm{~g}$ & $7,3 \mathrm{~g}$ \\
Água destilada & $1.000 \mathrm{~mL}$ & $1.000 \mathrm{~mL}$ & $1.000 \mathrm{~mL}$ \\
\hline
\end{tabular}


epifluorescência foram contabilizados 100 espermatozoides, classificados em integros, semilesados e lesados. Os espermatozoides íntegros coram-se pelo diacetato de carboxifluresceína (verdes em toda extensão), os semilesados, o acrossomo e a membrana coram-se pelo diacetato de carboxifluresceína, mas o núcleo cora-se com iodeto de propídeo (vermelho) e os lesados coram-se de vermelho.

Para análise dos dados, foi utilizado o software SAEG, versão 9.1.(SAEG-UFV, 2007). Os dados foram delineados em esquema fatorial com dois tipos de sêmen, três tempos de incubação e quatro osmolaridades das soluções hiposmóticas, sendo 24 tratamentos por ejaculado. Análises descritivas quanto às médias, aos desvios-padrão e aos coeficientes de variação foram feitas para todas as características estudadas. O teste Lilliefors foi utilizado para verificação de normalidade das respostas das variáveis estudadas. A homogeneidade das variâncias entre grupos de tratamento foi estudada, utilizando-se o teste de Cochran-Bartlett. A análise de variância foi utilizada para avaliar o efeito dos tempos de incubação e osmolaridade da solução hiposmótica no teste hiposmótico. Foram avaliados os efeitos entre touros e do mesmo touro sobre os aspectos físicos e morfológicos do sêmen, teste hiposmótico e de termorresistência lento. Quando foi detectado efeito pelo teste $\mathrm{F}$, as médias foram comparadas pelo teste t e o teste de Tukey (5\%). O teste de KruskalWallis (5\%) foi realizado para a análise do efeito dos touros para as características turbilhonamento, concentração espermática do ejaculado, e o percentual de espermatozoides reativos do sêmen congelado/descongelado após o teste hiposmótico. Correlação simples de Pearson foi realizada entre as características seminais e os testes complementares empregados. Testaram-se as interações entre os tipos de sêmen (congelado/descongelado e in natura), três tempos de incubação e quatro osmolaridades de solução hiposmótica.

\section{Resultados e Discussão}

Os touros foram classificados como aptos à reprodução segundo os critérios preconizados pelo Colégio Brasileiro de Reprodução Animal (CBRA, 1998). Os valores de circunferência escrotal (34,4 $\pm 2,6 \mathrm{~cm}$ ) e peso corporal (688 $\pm 122 \mathrm{~kg}$ ) foram normais para o manejo utilizado e a idade.

Os valores médios da motilidade progressiva retilínea e do vigor espermático apresentaram variação entre os touros $(\mathrm{P}<0,05)$, mas o turbilhonamento e a concentração espermática por mL não apresentaram variação (Tabela 2). As médias dos percentuais de defeitos espermáticos maiores e totais $(\mathrm{P}<0,05)$ foram diferentes entre os touros, mas não foi observada diferença entre touros quanto aos percentuais de defeitos menores (Tabela 2). Valores semelhantes para os aspectos físicos e morfológicos do sêmen in natura foram observados por Borges (2008) e Vera-Munoz (2009). Borges (2008) observou médias superiores de turbilhonamento, concentração espermática por $\mathrm{mL}$ em milhões e vigor (4,2, 1.468 e 4,4 respectivamente), mas uma média semelhante de motilidade espermática retilínea progressiva $(76,8 \%)$ no sêmen in natura. Borges (2008) também observou maiores médias de defeitos espermáticos maiores (15,1\%), menores $(4,7 \%)$ e totais (19,9\%) no sêmen in natura. Ao congelar sêmen de touros mestiços (Bos taurus $\times$ Bos indicus), Vera-Munoz et al. (2009) observaram 21,4\% de defeitos totais na análise morfológica do sêmen in natura. Brito et al. (2002), analisando a qualidade seminal de 68 touros zebuínos de central de inseminação artificial no Brasil, observaram motilidade espermática progressiva retilínea do ejaculado menor que a determinada neste experimento (59,3\%), mas resultados muito semelhantes em relação à morfologia espermática (12,3\% de defeitos maiores, 5\% de defeitos menores e $17 \%$ de defeitos totais).

O percentual de espermatozoides reativos no teste hiposmótico do sêmen in natura foi maior $(\mathrm{P}<0,05)$ que no

Tabela 2 - Aspectos físicos e morfológicos do sêmen in natura de touros adultos da raça Nelore

\begin{tabular}{|c|c|c|c|c|c|c|c|}
\hline \multirow[t]{2}{*}{ Touro } & \multicolumn{4}{|c|}{ Aspecto físico } & \multicolumn{3}{|c|}{ Aspecto morfológico } \\
\hline & $\begin{array}{l}\text { Motilidade } \\
\text { retilínea (\%) }\end{array}$ & $\begin{array}{c}\text { Vigor } \\
\text { espermático } \\
(0 \text { a } 5)\end{array}$ & $\begin{array}{l}\text { Turbilhão } \\
\text { (0 a 5) }\end{array}$ & $\begin{array}{c}\text { Concentração } \\
\text { espermática } \\
\left(10^{6} \text { células } / \mathrm{mL}\right)\end{array}$ & $\begin{array}{c}\text { Defeitos } \\
\text { espermáticos } \\
\text { maiores }\end{array}$ & $\begin{array}{l}\text { Defeitos } \\
\text { espermáticos } \\
\text { menores }\end{array}$ & $\begin{array}{c}\text { Defeitos } \\
\text { espermáticos } \\
\text { totais }\end{array}$ \\
\hline 1 & $84,0 \pm 4,1 \mathrm{a}$ & $3,7 \pm 0,2 a$ & $3,3 \pm 0,4 \mathrm{~A}$ & $792 \pm 213 \mathrm{~A}$ & $4,7 \pm 1,4 c$ & $1,9 \pm 1,2 \mathrm{a}$ & $6,6 \pm 1,6 b$ \\
\hline 2 & $81,2 \pm 4,1 \mathrm{ab}$ & $3,3 \pm 0,2 \mathrm{ab}$ & $2,0 \pm 0,7 \mathrm{~A}$ & $710 \pm 343 \mathrm{~A}$ & $7,7 \pm 1,8 \mathrm{bc}$ & $2,1 \pm 0,4 a$ & $9,8 \pm 1,7 \mathrm{ab}$ \\
\hline 3 & $79,0 \pm 6,5 \mathrm{ab}$ & $3,2 \pm 0,4 \mathrm{ab}$ & $3,1 \pm 0,7 \mathrm{~A}$ & $890 \pm 383 \mathrm{~A}$ & $12,7 \pm 2,7 a b$ & $3,7 \pm 2,7 a$ & $16,4 \pm 5,4 a$ \\
\hline 4 & $79,0 \pm 5,4 \mathrm{ab}$ & $3,0 \pm 0,1 b$ & $2,6 \pm 0,6 \mathrm{~A}$ & $518 \pm 126 \mathrm{~A}$ & $14,7 \pm 4,1 \mathrm{a}$ & $2,0 \pm 1,6 a$ & $17,5 \pm 5,6 a$ \\
\hline 5 & $69,0 \pm 10,2 b$ & $3,2 \pm 0,4 \mathrm{ab}$ & $2,5 \pm 1,7 \mathrm{~A}$ & $908 \pm 713 \mathrm{~A}$ & $11,6 \pm 2,7 a b$ & $3,1 \pm 1,7 a$ & $14,7 \pm 3,8 \mathrm{a}$ \\
\hline 6 & $79,0 \pm 8,2 \mathrm{ab}$ & $3,0 \pm 0,3 b$ & $2,6 \pm 0,8 \mathrm{~A}$ & $700 \pm 201 \mathrm{~A}$ & $11,7 \pm 3,9 a b$ & $3,4 \pm 2,1 a$ & $15,1 \pm 3,4 a$ \\
\hline Média & $78,5 \pm 7,7$ & $3,2 \pm 0,3$ & $2,6 \pm 0,9$ & $753 \pm 372$ & $10,5 \pm 4,3$ & $2,8 \pm 1,7$ & $13,3 \pm 5,3$ \\
\hline
\end{tabular}

a,b,c $=$ Letras minúsculas diferentes na mesma coluna indicam diferença significativa $(P<0,05)$ pelo teste Tukey a $5 \%$.

A,B,C = Letras maiúsculas diferentes na mesma coluna indicam diferença significativa $(\mathrm{P}<0,05)$ pelo teste Kruskal-Wallis a $5 \%$. 
sêmen congelado/descongelado (Tabela 3), devido aos danos causados à membrana plasmática pelo processo de criopreservação, corroborando os resultados descritos por Borges (2008) e Vera-Munoz et al. (2009). Borges (2008) verificou 66\% de espermatozoides reativos no teste hiposmótico em sêmen in natura e 50\% em sêmen congelado/descongelado. Vera-Munoz et al. (2009) obtiveram média de $68,1 \%$ de espermatozoides reativos ao teste hiposmótico no sêmen in natura e 48,8\% para sêmen congelado/descongelado de touros mestiços. Neste estudo, foi observada, após o processo de criopreservação, uma perda de $40 \%$ da motilidade progressiva retilínea espermática, valor aceitável, conforme reportado por Watson (2000). Houve perda de 33,5\% dos espermatozoides íntegros encontrados no teste supravital, e $49 \%$ no teste hiposmótico após o processo de criopreservação. O processo de criopreservação promove danos às membranas plasmáticas dos espermatozoides alterando seus domínios e a função de várias proteínas (proteínas transportadoras de íons, por exemplo) importantes no metabolismo espermático. As mudanças de temperatura, estresse osmótico e toxicidade devidas ao uso de crioprotetores e à formação e dissolução dos cristais no ambiente extracelular são as principais causas de injúrias subletais e letais aos espermatozoides (Watson, 2000). Borges (2008) e Vera-Munoz (2009), no entanto, utilizaram touros em central de inseminação artificial, onde o processo de criopreservação é realizado com mais eficiência, grande parte realizada de forma industrial.

Os aspectos físicos (motilidade progressiva retilínea e vigor espermático) pós-descongelamento não diferiram entre os ejaculados dos diferentes touros ( $\mathrm{P}>0,05)$ (Tabela 4). Não foram detectadas diferenças $(\mathrm{P}>0,05)$ entre as médias dos aspectos físicos do sêmen dos touros após a realização do teste de termorresistência (Tabela 4). As médias da motilidade progressiva retilínea espermática do sêmen congelado e após a realização do teste de termorresistência lento foram mais baixas que as observadas por outros autores em touros adultos da raça Nelore. Siqueira et al. (2007) e Borges (2008) observaram 53,4\% e 52,1\% para a motilidade espermática progressiva retilínea ao descongelamento, e 33,04\% e 34,44\% após a realização do teste de termorresistência lento. Isso se deve ao fato de que 23,3\% das partidas não são classificadas como aptas ao uso em programas de inseminação artificial segundo os critérios do Colégio Brasileiro de Reprodução Animal (1998), e esses autores utilizaram touros da raça Nelore de centrais de inseminação artificial, onde todas as amostras utilizadas foram classificadas aptas ao uso em programas de inseminação artificial. Mocé \& Graham (2008) observaram pequena diminuição da motilidade progressiva retilínea espermática (de 47,6\% para 41\%) após as 3 horas de incubação no teste de termorresistência em sêmen de touros da raça holandesa em central de inseminação artificial.

Tabela 3 - Resultados dos testes supravital e hiposmótico em sêmen in natura e congelado/descongelado de touros adultos da raça Nelore

\begin{tabular}{cccccc}
\hline \multirow{2}{*}{ Touros } & \multicolumn{2}{c}{ Sêmen in natura } & & \multicolumn{2}{c}{ Sêmen congelado/descongelado } \\
\cline { 2 - 3 } \cline { 5 - 6 } & Teste supravital (\%) & Teste hiposmótico (\%) & & Teste supravital (\%) & Teste hiposmótico (\%) \\
\hline 1 & $81,0 \pm 4,9 \mathrm{a}$ & $52,2 \pm 20,7 \mathrm{c}$ & $59,6 \pm 9,1 \mathrm{a}$ & $25,1 \pm 7,4 \mathrm{C}$ \\
2 & $77,4 \pm 6,1 \mathrm{a}$ & $64,6 \pm 16,4 \mathrm{~b}$ & $62,5 \pm 21,0 \mathrm{~b}$ & $57,6 \pm 12,7 \mathrm{a}$ & $33,6 \pm 7,4 \mathrm{AB}$ \\
3 & $82,8 \pm 3,4 \mathrm{a}$ & $50,6 \pm 19,8 \mathrm{c}$ & & $36,6 \pm 5,8 \mathrm{a}$ & $31,8 \pm 9,1 \mathrm{~B}$ \\
4 & $74,0 \pm 11,1 \mathrm{a}$ & $52,3 \pm 18,9 \mathrm{c}$ & & $55,0 \pm 16 \mathrm{a}$ & $26,5 \pm 7,8 \mathrm{BC}$ \\
5 & $73,2 \pm 13,4 \mathrm{a}$ & $79,0 \pm 17,7 \mathrm{a}$ & & $38,2 \pm 14,1 \mathrm{a}$ & $27,2 \pm 15,6 \mathrm{C}$ \\
6 & $75,2 \pm 7,1 \mathrm{a}$ & $60,3 \pm 21,6$ & & $61,4 \pm 18,1 \mathrm{a}$ & $40,4 \pm 13,4 \mathrm{~A}$ \\
Média & $77,2 \pm 8,4$ & & & $51,4 \pm 15,8$ & $30,8 \pm 11,8$ \\
\hline
\end{tabular}

a,b,c = Letras minúsculas diferentes na mesma coluna indicam diferença $(\mathrm{P}<0,05)$ pelo teste Tukey a $5 \%$.

A,B,C $=$ Letras maiúsculas diferentes na mesma coluna indicam diferença $(\mathrm{P}<0,05)$ pelo teste Kruskal-Wallis a $5 \%$.

Tabela 4 - Aspectos físicos do sêmen congelado/descongelado de touros adultos da raça Nelore após 3 horas de incubação (teste de termorresistência)

\begin{tabular}{|c|c|c|c|c|c|c|}
\hline \multirow[t]{2}{*}{ Touro } & \multicolumn{3}{|c|}{ Motilidade retilínea progressiva dos espermatozoides (\%) } & \multicolumn{3}{|c|}{ Vigor espermático (0-5) } \\
\hline & Motilidade & Motilidade $3^{a}$ hora & Redução da motilidade & Vigor & Vigor $3^{\mathrm{a}}$ hora & Redução do vigor \\
\hline 1 & $54 \pm 6,5 a$ & $36 \pm 5,4 a$ & $18 \pm 10,3 a$ & $3,2 \pm 0,2 \mathrm{a}$ & $2,8 \pm 0,4 a$ & $0,4 \pm 0,6 a$ \\
\hline 2 & $49 \pm 9,6 a$ & $27 \pm 6,7 a$ & $22 \pm 10,4 a$ & $2,9 \pm 0,4 a$ & $2,2 \pm 0,2 \mathrm{a}$ & $0,7 \pm 0,4 a$ \\
\hline 3 & $44 \pm 9,6 a$ & $20 \pm 13,6 a$ & $24 \pm 17,1 \mathrm{a}$ & $2,7 \pm 0,2 a$ & $2 \pm 0,7 a$ & $0,7 \pm 0,6 a$ \\
\hline 4 & $46 \pm 11,9 a$ & $25 \pm 16,5 a$ & $21 \pm 6,5 a$ & $3,0 \pm 0,1 a$ & $1,8 \pm 1,1 \mathrm{a}$ & $1,2 \pm 1 \mathrm{a}$ \\
\hline 5 & $39 \pm 14,7 a$ & $11 \pm 16,7 a$ & $28 \pm 2,7 a$ & $2,6 \pm 0,4 a$ & $1,2 \pm 1,3 a$ & $1,4 \pm 1 a$ \\
\hline 6 & $51 \pm 17,8 a$ & $32 \pm 17,8 a$ & $19 \pm 8,9 a$ & $3,2 \pm 0,4 a$ & $2,6 \pm 0,4 a$ & $0,6 \pm 0,4 a$ \\
\hline Média & $47,1 \pm 12,2$ & $25,1 \pm 14,9$ & $22 \pm 9,9$ & $2,9 \pm 0,3$ & $2,1 \pm 0,9$ & $0,8 \pm 0,7$ \\
\hline
\end{tabular}

a,b,c = Letras minúsculas iguais na mesma coluna indicam que não houve diferença $(\mathrm{P}<0,05)$ pelo teste Tukey a $5 \%$. 
Recentemente Vianna et al. (2009), utilizando touros da raça Nelore em um programa de inseminação artificial, compararam amostras classificadas como de altas e baixas congelabilidade (utilizando o teste de termorresistência lento e análise computadorizada de motilidade espermática para a classificação) e não observaram diferenças nas taxas de gestação. Esses autores concluíram que o teste de termorresistência não mimetiza as condições uterinas e a sobrevivência dos espermatozoides no trato genital da vaca, e não pode ser utilizado para predizer a fertilidade das amostras de sêmen, haja vista a grande influência de várias substâncias presentes no trato genital da vaca, que possuem papel fundamental no metabolismo e na sobrevivência dos espermatozoides até o momento da fertilização.

O percentual de células espermáticas viáveis registradas no teste supravital no sêmen congelado/descongelado $(51,4 \%)$ (Tabela 3$)$ foi menor que o observado por Tanghe et al. (2002) (69,5\%) em touros taurinos. Motilidade espermática progressiva retilínea média menor que a deste experimento (47,1\%) foi observada por Tanghe et al. (2002). Esses autores observaram que, após descongelamento, o percentual de espermatozoides íntegros no teste supravital foi maior nos touros com alta fertilidade na produção de embriões in vitro. Neste estudo não foram observadas diferenças $(\mathrm{P}>0,05)$ nos percentuais de células íntegras no teste supravital entre os ejaculados dos diferentes touros, no sêmen in natura e no sêmen congelado/descongelado (Tabelas 3 e 5).

A média de espermatozoides reativos no teste hiposmótico (Tabela 3) foi semelhante à descrita por Siqueira et al. (2007) (37,89\%), que utilizaram sêmen congelado/descongelado de touros adultos da raça Nelore. Mocé \& Graham (2008) obtiveram média de 44,69\% espermatozoides reativos após o teste hiposmótico no sêmen de touros da raça holandesa. Correa et al. (1997) e Bacinoglu et al. (2008), utilizando touros da raça holandesa classificados de baixa e alta fertilidade em programas de inseminação artificial, não observaram diferenças na motilidade espermática retilínea progressiva após o descongelamento entre as classes de touros. Correa et al. (1997) verificaram diferenças entre as médias dos percentuais de espermatozoides reativos no teste hiposmótico dos touros classificados como de baixa e alta fertilidade, sendo $31,7 \%$ para touros de baixa fertilidade e $41,9 \%$ para touros de alta fertilidade. Bacinoglu et al. (2008) não verificaram diferenças nos resultados do teste hiposmótico entre touros de baixa e alta fertilidade.

Foram detectadas diferenças entre os animais no teste hiposmótico do sêmen in natura e congelado/descongelado $(\mathrm{P}<0,05)$. O touro 6 foi superior $(\mathrm{P}<0,05)$, quanto ao teste hiposmótico no sêmen in natura e congelado (Tabela 3), e apresentou valores intermediários para os aspectos físicos e morfológicos do ejaculado (Tabela 2) e para os testes complementares utilizados no sêmen congelado (Tabela 5). Apenas os touros 1, 2 e 6 apresentaram todos os ejaculados e congelamentos dentro dos critérios preconizados pelo Colégio Brasileiro de Reprodução Animal (1998), sendo considerados touros de alta congelabilidade. Os touros 3 e 4 tiveram 20\% das partidas de sêmen congelado fora dos padrões preconizados pelo CBRA (1998), e o touro 5 apresentou $80 \%$ das amostras congeladas fora do padrão, sendo o animal que apresentou os piores resultados de congelamento $(\mathrm{P}<0,05)$. $\mathrm{O}$ touro 5 pode ser considerado de baixa congelabilidade, devido aos resultados durante o período experimental. O teste hiposmótico no sêmen in natura foi capaz de mostrar a superioridade do touro 6 $(\mathrm{P}<0,05)$ e não foi verificada superioridade dos touros 1 e 2 , sendo o touro 1 semelhante ao touro 5 (baixa congelabilidade do sêmen). As médias dos resultados dos testes complementares tanto em sêmen in natura e congelado/ descongelado dos touros 1 e 5 não diferiram (Tabelas 3, 4 e 5), mas quando se compara a freqüência de congelamentos de acordo com as normas de qualidade (CBRA, 1998) o touro 1 é muito superior $(\mathrm{P}<0,05)$.

A microrscopia de epiflorescência se mostrou mais sensível para detectar danos as membranas dos espermatóides

Tabela 5 - Resultados dos testes supravital, hipósmótico e da coloração fluorescente no sêmen congelado/descongelado de touros adultos da raça Nelore

\begin{tabular}{|c|c|c|c|c|c|}
\hline \multirow[b]{2}{*}{ Touros } & \multirow[b]{2}{*}{ Teste supravital (\%) } & \multirow[b]{2}{*}{ Teste hiposmótico (\%) } & \multicolumn{3}{|c|}{ Microscopia de epifluorescência (\%) } \\
\hline & & & Intacto & Parcialmente lesado & Lesado \\
\hline 1 & $59,6 \pm 9,1 \mathrm{a}$ & $25,1 \pm 7,4 \mathrm{C}$ & $24 \pm 8,7 \mathrm{ab}$ & $23,2 \pm 8,4 a$ & $52,8 \pm 13,9 a b$ \\
\hline 2 & $57,6 \pm 12,7 a$ & $33,6 \pm 7,4 \mathrm{AB}$ & $12,8 \pm 9,1 b$ & $23,2 \pm 7,5 a$ & $64,1 \pm 12,6 a b$ \\
\hline 3 & $36,6 \pm 5,8 a$ & $31,8 \pm 9,1 \mathrm{~B}$ & $33,8 \pm 11,1 \mathrm{a}$ & $21,4 \pm 8,2 \mathrm{a}$ & $44,8 \pm 7,7 \mathrm{ab}$ \\
\hline 4 & $55,0 \pm 16 a$ & $26,5 \pm 7,8 \mathrm{BC}$ & $23,5 \pm 12,8 a b$ & $16,5 \pm 6,7 \mathrm{a}$ & $60,1 \pm 19,4 \mathrm{ab}$ \\
\hline 5 & $38,2 \pm 14,1 \mathrm{a}$ & $27,2 \pm 15,6 \mathrm{C}$ & $15,2 \pm 5,7 a b$ & $20 \pm 12,1 a$ & $64,8 \pm 11,2 \mathrm{a}$ \\
\hline 6 & $61,4 \pm 18,1 \mathrm{a}$ & $40,4 \pm 13,4 \mathrm{~A}$ & $28,4 \pm 9,9 a b$ & $34,2 \pm 7,9 a$ & $37,4 \pm 16,9 b$ \\
\hline Média & $51,4 \pm 15,8$ & $30,8 \pm 11,8$ & $22,9 \pm 11,5$ & $23,3 \pm 9,5$ & $53,75 \pm 16,33$ \\
\hline
\end{tabular}

a,b,c = letras minúsculas diferentes na mesma coluna indicam diferença $(\mathrm{P}<0,05)$ pelo teste Tukey a $5 \%$.

A,B,C = letras maiúsculas diferentes na mesma coluna indicam diferença $(\mathrm{P}<0,05)$ pelo teste Kruskal-Wallis a $5 \%$. 
comparando aos outros testes complementares utilizados neste experimento, com percentuais de espermatozoides viáveis inferiores ao teste hiposmótico e supravital, corroborando os resultados de Borges (2008) e Brito et al. (2003).

Neste estudo não foi detectada diferença entre os valores médios obtidos no teste hiposmótico empregando-se as osmolaridades de 60, 100 e $150 \mathrm{mOsm} / \mathrm{kg}$ para o sêmen in natura $(\mathrm{P}>0,05)$, apenas diferindo $(\mathrm{P}<0,05)$ os valores médios obtidos no teste hiposmótico empregando-se a água destilada $(19 \mathrm{mOsm} / \mathrm{kg})$. No sêmen congelado/ descongelado, não foram detectadas diferenças $(\mathrm{P}>0,05)$ para os valores médios de espermatozoides reativos incubados nas soluções com diferentes osmolaridades para o sêmen congelado/descongelado (Tabela 6), resultados que divergem dos relatos de Revell \& Mrode (1994), que testaram diferentes osmolaridades e tempos de incubação pelo teste hiposmótico, e concluíram, com base na correlação com os resultados de prenhez dos touros taurinos em programas de inseminção artificial, que a osmolaridade de $150 \mathrm{mOsm} / \mathrm{kg}$ com o tempo de incubação de 1 hora é a mais adequada para a realização do teste no sêmen in natura, e $100 \mathrm{mOsm} / \mathrm{kg}$ com 1 hora de incubação para o sêmen congelado/descongelado.

Não foram observadas diferenças entre os tempos de incubação para o sêmen in natura e o congelado/ descongelado $(\mathrm{P}>0,05)$ (Tabela 7$)$, e isso indica que os espermatozoides reativos dobram a cauda no início da incubação, não necessitando mais que 15 minutos para a realização do teste hiposmótico. Os resultados do experimento não confirmam os achados de Revell \& Mrode (1994), que observaram diferenças entre 20 minutos de incubação em solução hiposmótica e 1 hora e preconizaram como ideal a incubação por 1 hora ao correlacionar com os resultados de fertilidade das amostras congeladas em programas de inseminção artificial.

Correlações positivas e médias foram observadas do teste supravital realizado em sêmen in natura com a

Tabela 6 - Resultados do teste hiposmótico em sêmen in natura e congelado/descongelado de touros adultos da raça Nelore utilizando diferentes osmolaridades

\begin{tabular}{ccc}
\hline Osmolaridade & \multicolumn{2}{c}{ Espermatozoides reativos (\%) } \\
\cline { 2 - 3 } & Sêmen in natura & Sêmen congelado/descongelado \\
\hline 19 & $42,8 \pm 17,2 \mathrm{~b}$ & $31,1 \pm 11,2 \mathrm{a}$ \\
60 & $62,2 \pm 19,8 \mathrm{a}$ & $31,7 \pm 12,8 \mathrm{a}$ \\
100 & $67,1 \pm 20,4 \mathrm{a}$ & $31,3 \pm 11,8 \mathrm{a}$ \\
150 & $69,4 \pm 18,2 \mathrm{a}$ & $31,6 \pm 10,9 \mathrm{a}$ \\
Média & $60,3 \pm 21,6$ & $30,8 \pm 11,8$ \\
\hline
\end{tabular}

a,b,c $=$ Letras minúsculas diferentes na mesma coluna indicam diferença $(P<0,05)$ pelo teste Tukey a $5 \%$. motilidade espermática progressiva retilínea $(\mathrm{r}=0,56)$ e 0 turbilhonamento $(r=0,35)$, e correlações positivas e altas foram observadas do teste supravital em sêmen congelado/ descongelado com a motilidade progressiva retilínea e vigor espermático após o descongelamento ( $\mathrm{r}=0,75$ e r $=0,62$, respectivamente) e a motilidade espermática progressiva retilínea e vigor espermático após as 3 horas de incubação no teste de termoresistência ( $r=0,82$ e r=0,69, respectivamente). A integridade física da membrana plasmática tem uma relação com a qualidade do ejaculado e de amostras congeladas/ descongeladas.

Os percentuais de espermatozoides reativos no teste hiposmótico em sêmen congelado se correlacionaram com a motilidade espermática progressiva retilínea e o vigor espermático após o descongelamento com valores positivos e médios ( $\mathrm{r}=0,38$ e $\mathrm{r}=0,34$, respectivamente), corroborando os achados de Borges (2008) $(0,49)$ e Siqueira et al. (2007) $(\mathrm{r}=0,21)$, sendo inferiores aos de Vera-Munoz et al. (2009) com correlação alta e positiva $(\mathrm{r}=0,96)$. A motilidade espermática progressiva retilínea e o vigor espermático após as 3 horas de incubação no teste de termoresistência correlacionaram-se com o teste hiposmótico, com valores médios e positivos ( $\mathrm{r}=0,41$ e $\mathrm{r}=0,37$, respectivamente), diferente de Siqueira et al (2007), que registraram correlação alta e positiva $(r=0,64)$. O teste supravital em sêmen congelado correlacionou-se, com valores médios e positivos, com o teste hiposmótico $(\mathrm{r}=0,39)$, corroborando os achados de Brito et al., (2003), e o percentual de espermatozoides íntegros na coloração fluorescente em sêmen congelado $(0,40)$. Brito et. al. (2003) obtiveram valor alto e positivo $(r=0,63)$ de correlação entre os resultados do teste hiposmótico e a coloração fluorescente. Correlações médias e negativas foram observadas entre o percentual de espermatozoides lesados na coloração fluorescente em sêmen congelado e o teste supravital $(\mathrm{r}=-0,32)$ e a motilidade espermática progressiva retilínea após as 3 horas de incubação no teste de termoresistência $(r=-0,30)$. A integridade física da membrana plasmática (teste supravital)

Tabela 7 - Resultados do teste hiposmótico no sêmen in natura e congelado/descongelado de touros adultos da raça Nelore utilizando diferentes tempos de incubação

\begin{tabular}{|c|c|c|}
\hline \multirow{2}{*}{$\begin{array}{l}\text { Tempo } \\
\text { (minutos) }\end{array}$} & \multicolumn{2}{|c|}{ Espermatozoides reativos (\%) } \\
\hline & Sêmen in natura & Sêmen congelado/descongelado \\
\hline 15 & $61,4 \pm 21,2 a$ & $30,7 \pm 11,6 a$ \\
\hline 30 & $60,5 \pm 22,1 a$ & $31,1 \pm 11,8 a$ \\
\hline 60 & $59,1 \pm 21,6 a$ & $30,6 \pm 12,1 \mathrm{a}$ \\
\hline Média geral & $60,3 \pm 21,6$ & $30,8 \pm 11,8$ \\
\hline
\end{tabular}

a,b,c $=$ Letras minúsculas diferentes na mesma coluna indicam diferença $(\mathrm{P}<0,05)$ pelo teste Tukey a 5\%; Hipo $(\mathrm{N})=$ Percentual de espermatozoides reativos do sêmen in natura após o teste hiposmótico; Hipo $(\mathrm{C} / \mathrm{D})=$ Percentual de espermatozoides reativos do sêmen congelado/descongelado após o teste hiposmótico. 
mostrou-se uma ferramenta importante na avaliação da qualidade do sêmen congelado/descongelado, visto a sua alta correlação com o principal teste complementar de qualidade de sêmen congelado (teste de termorresistência lento), segundo as normas de comercialização publicada pelo Ministério da Agricultura e do Abastecimento, portaria nº 005/1996 (CBRA, 1998). O teste hiposmótico e a coloração fluorescente não se correlacionaram entre si, discordando dos resultados de Brito et al. (2003), mas se correlacionaram com coeficientes médios com os principais aspectos de qualidade seminal do sêmen congelado, corroborando com os achados de Borges (2008). Os resultados do teste hiposmótico tanto em sêmen in natura e congelado/ descongelado e dos testes de integridade física da membrana plasmática não foram eficientes em classificar os touros zebuínos quanto à congelabilidade do sêmen.

\section{Conclusões}

O teste hiposmótico e a coloração fluorescente são ferramentas importantes para avaliação de sêmen bovino congelado/descongelado. O teste hiposmótico pode ser realizado com 15 minutos de incubação utilizando solução que varie a osmolaridade de 60 a $150 \mathrm{mOsm} / \mathrm{kg}$, tanto em sêmen in natura como no sêmen congelado/descongelado de touros adultos da raça Nelore.

\section{Referências}

BACINOGLU, S.; TAS, M.; CIRIT, U. et al. The potential fertility estimation capacity of the hypoosmotic swelling test, the thermal stress test and a modified cervical mucus penetration test in the bovine. Animal Reproduction Science, v.104, p.38-46, 2008.

BORGES, J.C. Efeito da utilização de antioxidante no diluidor para a criopreservação de sêmen bovino avaliado através de testes complementares, inseminação artificial e fecundação in vitro. 2008. 70f. Tese (Doutorado em Medicina Veterinária) - Universidade Estadual Paulista, Jaboticabal.

BRITO, L.F.C.; SILVA, A.E.D.F.; RODRIGUES, L.H. et al. Effect of age and genetic group on characteristics of the scrotum, testes and testicular vascular cones, and on sperm production and semen quality in AI bulls in Brazil. Theriogenology, v.58, p.1175-1186, 2002.

BRITO, L.F.C.; BARTH, A.D.; BILODEAU-GOESEELS, S. et al. Comparison of methods to evaluate the plasmalemma of bovine sperm and their relationship with in vitro fertilization rate. Theriogenology, v.60, p.1539-1551, 2003.

COLÉGIO BRASILEIRO DE REPRODUÇÃO ANIMAL - CBRA. Manual para exame andrológico e avaliação de sêmen animal. 2.ed. Belo Horizonte, 1998. 49p.

CORREA, J.R. ; ZAVOS, P.M. The hypoosmotic swelling test : it's employment as an assay to evaluate the functional integrity of the frozen-thawed bovine sperm membrane. Theriogenology, v.42, p.351-360, 1994.

CORREA, J.R.; PACE, M.M.; ZAVOS, P.M. Relationship among frozenthawed sperm characteristics assessed via routine semen analysis, sperm functional tests and fertility of bulls in an artificial insemination program. Theriogenology, v.48, p.721-731, 1997.

HARRISON, R.A.; VICKERS, S.E. Use of fluorescent probes to assess membrane integrity in mammalian spermatozoa. Journal of Reproduction and Fertility, v.88, p.343-52, 1990.

HENRIQUES, G.S.; ROSADO, G.P. Formulação de dietas enterais artesanais e determinação da osmolaridade pelo método crioscópico. Revista de Nutrição de Campinas, v.12, p.225-232, 1999.

MELO, M.I.V.; HENRY, M. Teste hiposmótico na avaliação de sêmen eqüino. Arquivo Brasileiro de Veterinária e Zootecnia, v.51, n.1, p.71-78, 1999.

MOCÉ, E.; GRAHAM, J.K. In vitro evaluation of sperm quality. Animal Reproduction Science, v.105, p.104-118, 2008.

REVELL, S.G.; MRODE, R.A. An osmotic resistance test for bovine semen. Animal Reproduction Science, v.36, p.77-86, 1994.

SENGER, P.L. Principles and procedures for storing and using frozen bovines semen. In: MORROW, D.A. (Ed.) Current therapy in theriogenology. Philadelphia: W. B. Saunders 1986. p.162-174.

SIQUEIRA, J.B.; GUIMARÃES, J.D.; COSTA, E.P. et al. Relação da taxa de gestação com sêmen bovino congelado e testes de avaliação espermática in vitro. Revista Brasileira de Zootecnia, v.36, p.387-395, 2007.

SWANSON, E.W.; BEARDEN, H.J. An eosin-nigrosin stain for differentiating live and dead bovine spermatozoa. Journal of Animal Science, v.10, p.981-987, 1951.

TANGHE, S.; VAN SOOM, A.; STERCKX, V. et al. Assessment of different sperm quality parameters to predict in vitro fertility of bulls. Reproduction in Domestic Animals, v.37, v.127-137, 2002.

TARTAGLIONE, C.M.; RITTA, M.N. Prognostic value of spermatological parameters as predictors of in vitro fertility of frozen-thawed bull semen. Theriogenology, v.62, p.1245-1252, 2004.

UNIVERSIDADE FEDERAL DE VIÇOSA - UFV. Sistema de análise estatística e genética - SAEG versão 9.1. Viçosa, MG: Universidade Federal de Viçosa, Central de Processamento de Dados, 2007. p.68.

VERA-MUNOZ, O.; AMIRAT-BRIAND, L.; DIAZ, T. et al. Effect of semen dilution to low-sperm number per dose on motility and functionality of cryopreserved bovine spermatozoa using lowdensity lipoproteins (LDL) extender: comparison to Triladyl ${ }^{\circledR}$ and Bioxcell ${ }^{\circledR}$. Theriogenology, v.71, p.895-900, 2009.

VIANNA, F.P.; PAPA, F.O.; ZHAB, F.S. et al. Thermoresistance sperm tests are not predictive of potential fertility for cryopreserved bull semen. Animal Reproduction Science, v.113, p.279-282, 2009.

WATSON, P.F. The causes of fertility with cryopreserved semen. Animal Reproduction Science, v.61, p.481-492, 2000. 